\section{Going the extra mile to help local communities smile}

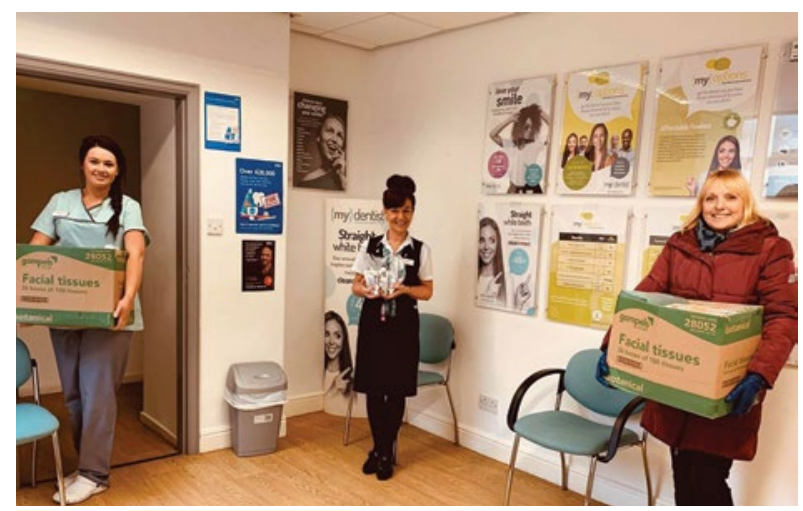

While dental practices have been closed for routine treatment, $\{$ my dentist practice teams around the UK have still been helping their local communities smile through acts of kindness.

From delivering prescriptions to simply calling elderly patients for a chat to ease the loneliness of social isolation the teams have done all they can to support people living nearby.

Just a handful of examples of community support from $\{\mathrm{my}\}$ dentist's team are below. The team has also been sharing stories, thanking their colleagues and keeping in touch via a new \{my\}dentist Facebook group which attracted nearly 3,000 members in two weeks.

After social distancing rules were announced, $\{$ my $\}$ dentist practices in East Lancashire decided to make sure none of their elderly or vulnerable patients were lonely. They got in touch for a chat, and gave practical help by running errands and shopping for essentials.

Rhian Slaymaker, treatment co-ordinator from $\{\mathrm{my}\}$ dentist New Road, New Town, decided to continue her voluntary work with a local nursing home by recording herself reading to them. Rhian often reads to the residents, so by recording herself she could continue while keeping everyone safe.

Meanwhile, the practice in Newtown also donated as many oral health products and kids' activity sheets as they could to the local food bank, and delivered prescriptions to people unable to leave their homes.

During the COVID-19 outbreak visiting in hospitals has been reduced. $\{$ my\}dentist Crickhowell put together a hamper of toiletries and activity packs for children and young patients at their local hospital to help them pass the time.

With the majority of practices closed to patients, $\{$ my\}dentist's procurement team was able to donate 300 bottles of badly needed hand sanitiser to the NHS. These were split between Manchester Children's Hospital and Bolton NHS Foundation Trust, close to its support centre.

Access to food has been difficult for the most vulnerable. \{my\} dentist Stroud decided to supply care packages to the homeless, and offered themselves up as a rest stop for emergency services to refill their travel mugs with tea and coffee. Meanwhile, $\{$ my $\}$ dentist practices in Dukinfield (pictured) and Hull have supported local care homes and charities to make sure elderly residents have enough to eat.

Chaitanya Kallisetty, a dentist from \{my\}dentist in Welshpool was so worried about one of his elderly patients being able to eat while they await a new denture that he went on a shopping trip to make sure they were well-stocked with soft foods and wouldn't have to leave the house.

\section{A helping hand for practices}

The Practice Plan Group, which includes two of the UK's leading membership plan providers, Practice Plan and DPAS, has announced that, in April and May, they will be giving back half of their monthly admin fee to their client practices to help them with cash flow throughout the COVID-19 crisis.

The move represents a significant investment on behalf of the Group and is part of a wider range of ongoing support measures introduced to help practice owners withstand the strain that the crisis is putting on their businesses.

Group Sales \& Marketing Director, Nigel Jones, explained: 'Many of our clients with well-populated membership plans are already seeing the smoothing benefits of regular payments coming into their practice throughout this crisis, but that doesn't solve the whole problem and cash flow is still a critical issue for many in their struggle to get through this difficult period.

'So, with the full support of our parent company, Wesleyan, we are delighted to say that we will be giving back half of our admin fee for the next two months at a time when, it appears, that many practices have fallen through the cracks of the Government's support for small businesses and the self-employed.

'We are also providing practices with advice, guidance and support via our dedicated support managers, regularly updated online resources (covid.practiceplangroup.co.uk) and an ever expanding programme of webinars covering topics such as employment law, mental health and practice finances.

'At the Practice Plan Group our approach has always been about working in partnership with our clients for the long-term and that philosophy has never been more important. By working in partnership, we can significantly boost our collective chances of a positive outcome.'

Practices do not need to do anything in order to receive the additional funds, they will be paid into their accounts automatically on their normal payment date.

\section{Absolutely hygienic for peace of mind}

COLTENE strives to provide dental professionals with the very best endodontic products possible - and a vital member of their Endo family is the ROEKO Guttapercha points.

Ideal for the obturation of the canal after endodontic treatment, the Guttapercha Points are easy to introduce to the canal, being stiff but flexible enough to follow the curves of the canal without breaking.

What's more, they are radiopaque and have excellent tissue compatibility for better outcomes. And as if this wasn't enough, Guttapercha Points are absolutely hygienic for added peace of mind.

COLTENE also uses the very latest manufacturing processes to ensure that all products are of the highest standard. ROEKO Guttapercha Points have been created using a fully automated production system that ensures each individual item is finished to exacting standards.

To find out more visit www.coltene.com, email info.uk@ coltene.com or call 01444235486. 